\begin{tabular}{c} 
journal homepage: http://ijiemjournal.uns.ac.rs/ \\
International Journal of Industrial \\
Engineering and Management \\
volume $11 /$ No $2 /$ June $2020 / 71-72$ \\
\hline
\end{tabular}

Editorial

\title{
EDITORIAL: \\ The IJIEM as a platform for engagement
}

\author{
Ugljesa Marjanovic
}

\author{
Editor-in-Chief, \\ International Journal of Industrial Engineering and Management \\ Professor of Industrial Engineering and Management \\ University of Novi Sad, \\ Faculty of Technical Sciences, \\ Novi Sad, Serbia \\ umarjano@uns.ac.rs
}

IJIEM was founded in 2010 by professor Dragutin Zelenovic and is one of the first journals in Serbia publishing research on industrial systems, production management and group technology. Today, IJIEM is a part of international community and recognized as a journal that publish high quality international research on industrial engineering, manufacturing engineering and engineering management. All papers were reviewed by at least two international referees and were accepted after at least a revision. It is with great sadness that we report the death of Professor Dragutin Zelenovic. His contribution to the IJIEM and to the industrial, production management, and manufacturing engineering community is colossal. Hence, this issue is dedicated to Professor Dragutin Zelenovic.

In this editorial, I present the papers of Volume 11, Issue 2, along with the Obituary to Professor Dragutin Zelenovic.

The article Cleaner Production Initiatives in a Diesel Engines Factory by L. F. R. Pinto, G. C. de Oliveira Neto, G. Mummolo, S. Digiesi, F. Facchini, and P. Centoamore presents a case study conducted in a Diesel engines manufacturer, which adopted a Cold Test machine to perform the final check of engines in the assembly line. The authors investigate and evaluate the economic and environmental advantages obtained by the adoption of the Cold Test machine.

C. A. Murad, A. H. de Andrade Melani, M. A. de Carvalho Michalski, A. C. Netto, G. F. M. de Souza, and S. I. Nabeta published paper OMCTA: A novel knowledge-based technique to evaluate the influence of O\&M actions on maintenance management. The authors suggest a new method, named OMCTA, based on techniques already known and widespread both in academia and industry. A case study is analysed, bringing results that clearly show the effects of the O\&M actions for different Kaplan turbine failure modes.

The next paper by C. Anusha, V. Umasankar Performance Prediction through OEE-Model deals with two 
different techniques, a simple moving average and Holt's double exponential smoothing methods, to evaluate OEE and to predict the future performance of overall equipment effectiveness in $\mathrm{R}$ studio.

The concept of 'talent' in the labor management perspective - the bibliometric analysis of literature by Y. Barkun, E. Rollnik-Sadowska, and E. Glinska provides an overview of literature review and bibliometric data analysis. The paper gives very interesting conclusions on the analysis of demand for talents from the business and regional perspectives.

In their article Strategic management accounting and strategic management: The mediating effect of performance evaluation and rewarding, P. Petera, J. Wagner, and L. Šoljaková investigate the mediating effect of performance evaluation and rewarding on the implementation of strategic management accounting into strategic management. A model was proposed and tested using partial least squares modeling.

Finally, the paper Servitization in manufacturing: role of antecedents and firm characteristics by U. Marjanovic, B. Lalic, N. Medic, J. Prester, and I. Palcic investigates the impact of service portfolio antecedents on firm performance and the direct vs. indirect charges of services and the interplay of different firm characteristics and the service business model. Results reveal antecedents as well as implications of direct and indirect charging of services in manufacturing firms. 